\title{
Association of Salivary Superoxide Dismutase and Nitric Oxide Levels in Patients With Smoking
}

\author{
Vaishali. S1 and Sreedevi Dharman ${ }^{2}$ \\ ${ }^{1}$ Saveetha Dental College and Hospitals Saveetha Institute of Medical \\ and Technical Sciences (SIMATS) Saveetha University,Chennai-600077, India \\ ${ }^{2}$ Reader Department of Oral Medicine and Radiology Saveetha Dental College \\ and Hospitals Saveetha Institute of Medical and Technical Sciences (SIMATS) \\ Saveetha University, Chennai, India
}

\section{ABSTRACT}

Saliva is the first fluid exposed during smoking and its antioxidant system plays an important role in anti-cancer potential. Aim of the study is to determine the influence of smoking on superoxide dismutase (SOD) enzyme and nitric oxide (NO) levels in saliva among smokers and non-smokers. 20 samples were taken among which 10 samples were of smokers and 10 samples were of non smokers. Collected unstimulated saliva samples were measured for levels of SOD and NO using spectrophotometric analysis. Levels of SOD were decreased in case of smokers (Mean $=4.95$, Standard error of mean= 0.0 .558 ) when compared to non smokers (Mean $=8.17$, Standard error of mean $=0.851$ ) hence statistically significant $(p=0.018)$. Levels of NO were elevated in case of smokers (Mean $=3.24$, Standard error of mean $=0.672)$ when compared to non smokers (Mean $=1.97$, Standard error of mean $=0.404$ ) hence statistically significant $(\mathrm{p}=0.032)$. Also, it was found that level of SOD decreased and NO increased as number of cigarette sticks and years of smoking increased which is statistically significant $(\mathrm{p}<0.05)$. Within the limits of the study, it is seen that there is a highly significant increase in NO and decrease in SOD in smokers when compared to non smokers. Also there is significant increase in level of NO and decrease in level of SOD as number of cigarettes and years of smoking increased.

\section{KEY WORDS: NITRIC OXIDE, ORAL LESIONS, PATHOGENESIS, SALIVA, SUPEROXIDE DISMUTASE, TOBACCO.}

\section{INTRODUCTION}

Smoking is a harmful habit that causes adverse effects on oral health and plays a most important role in cancer development (Golusinska-Kardach et al., 2015). Despite frequent notice of irreversible consequences of smoking in public media and by other forms of advertising, smoking habits are growing dramatically in both developed and

\section{ARTICLE INFORMATION}

*Corresponding Author: sreedevi@saveetha.com

Received 29th July 2020 Accepted after revision 28th Sep 2020

Print ISSN: 0974-6455 Online ISSN: 2321-4007 CODEN: BBRCBA

Thomson Reuters ISI Web of Science Clarivate Analytics USA and Crossref Indexed Journal

\section{Clarivate
Analytics}

NAAS Journal Score 2020 (4.31) SJIF: 2020 (7.728)

A Society of Science and Nature Publication,

Bhopal India 2020. All rights reserved.

Online Contents Available at: http//www.bbrc.in/

Doi: http://dx.doi.org/10.21786/bbrc/13.8/146 developing countries. Based on available statistics, even in previous years, almost one-third of the population over age 30 years are smokers (Zenzes, 2000). Smoking leads to changes in immune reaction and total antioxidant capacity. Smoking, through dysfunction of antioxidant systems, plays an important role in the pathogenesis of inflammatory diseases (Toker et al., 2012).

Saliva is the first fluid that is exposed to smoking and its antioxidant system plays an important role in anti-cancer potential.It has been confirmed that there is a direct relationship between oxidative stress and pathologic conditions or diseases. Assessment of the elements effective in oxidative stress on the body's fluids, such as saliva, could be beneficial for monitoring progression and treatment of some diseases (Rodgman and Perfetti, 2013). Tobacco smoking produces large amounts of reactive oxygen species (ROS), which have an influence on normal

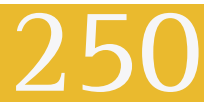


cellular function and causes changes in the inflammation markers (U. s. Department of Health and Human Services Staff, 2010) . Oxidative stress, which is produced through serious imbalance between the generation of reactive oxygen species and antioxidant protection, is effective in the pathogenesis of inflammatory conditions.

Reactive oxygen species (ROS) are chemically reactive molecules containing oxygen. Oxygen is a highly reactive atom that is capable of becoming part of potentially damaging molecules commonly called "free radicals (Mayne, 2003). The addition of one electron to di-oxygen forms the superoxide anion radical (02 • ). All free radicals are capable of reacting with membrane lipids, nucleic acids, proteins and enzymes, and other small molecules, resulting in cellular damage.

Table 1. Shows mean value of superoxide dismutase levels in smokers and non-smokers. SOD level is increased in non smokers when compared to smokers (Paired t test, $\mathrm{p}=0.018$ )

\begin{tabular}{|l|c|c|c|}
\hline $\begin{array}{l}\text { Superoxide Dismutase } \\
\text { (nmol/mg protein) }\end{array}$ & Mean & $\begin{array}{c}\text { Standard } \\
\text { error } \\
\text { of mean }\end{array}$ & $\begin{array}{c}\text { Paired } \\
\text { t-test }\end{array}$ \\
\hline Smokers & 4.95 & 0.558 & $\begin{array}{c}\mathrm{p} \text { value }= \\
0.018\end{array}$ \\
\hline Non Smokers & 8.17 & 0.851 & \\
\hline
\end{tabular}

Figure 1: Bar graphs depicts the mean salivary superoxide dismutase levels in smokers and non smokers. $\mathrm{X}$ axis denotes smokers and non smokers and $\mathrm{Y}$ axis denotes the mean SOD levels (nmol/mg protein). It is seen that SOD level is increased in non smokers when compared to smokers (Paired t test, $\mathrm{p}=\mathbf{0 . 0 1 8}$ )

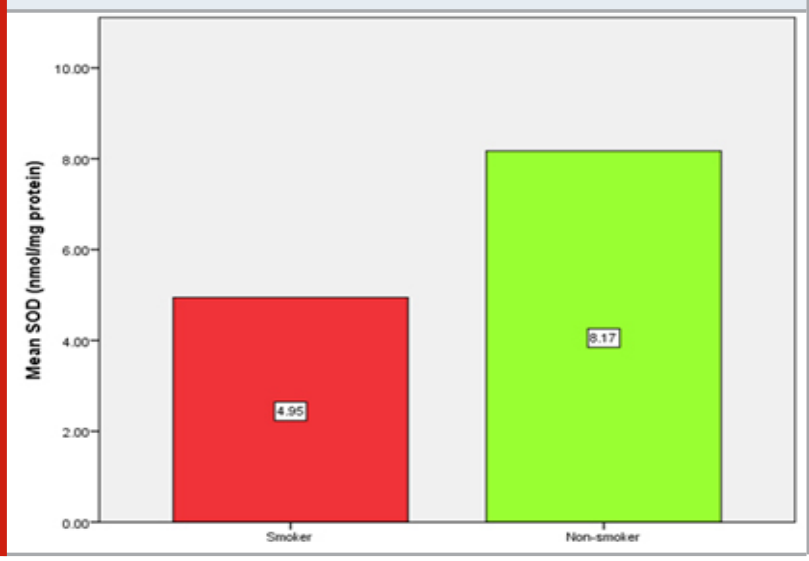

Superoxide Dismutase (SOD) catalyzes the conversion of superoxide radicals into hydrogen peroxide and molecular oxygen. SOD plays a critical role in the defense of cells against the toxic effects of oxygen radicals (Simic and Karel, 2013). It competes with nitric oxide (NO) for superoxide anions, which react with NO to form peroxynitrite, which is potential enough to cause DNA damage. Decrease in protective systems of antioxidants due to tobacco smoking may be a cause of many pathological conditions such as cardiovascular and respiratory disorders and even potentially malignant disorders. Assessment of antioxidant markers may be relevant in the evaluation of risks of such pathologic conditions and associated oxidative stress induced by smoking (Bolzán, Bianchi and Bianchi, 1997).

Nitric oxide (NO), a free radical, is synthesised from the amino acid L-arginine by the enzyme nitric oxide synthase (NOS). Nitric oxide, a signalling molecule, acts as a 'double-edged sword' affecting numerous physiological and pathological processes (Crowell et al., 2003). Low nitric oxide levels are associated with homeostatic actions such as immune functions, blood flow, platelet aggregation, neurotransmission, and memory, whereas excess nitric oxide production is involved in inflammatory and immunological disorders, pain, neurological diseases, atherosclerosis, and cancer. It also plays an important role in the occurrence and progression of tumours, involving mechanisms such as DNA damage, inducing tumour angiogenesis and promoting tumour invasion and metastasis by reacting with other free radicals to form peroxynitrite which causes DNA damage (Alcaraz and Guilln, 2002).

Our recent research portfolio slides numerous articles in reputed journals (Santosh R. Patil et al., 2018; S. R. Patil et al., 2018; Subramaniam and Muthukrishnan, 2019; Vadivel et al., 2019; Patil et al., 2020). Based on this experience we planned to pursue evaluation of superoxide dismutase and nitric oxide levels in smokers and non smokers.

\section{MATERIAL AND METHODS}

Study setting: It is a case control study, conducted in Saveetha Dental College from November 2019 to January 2020. Approval was obtained from the Institutional Ethical Committee (IEC), Saveetha Dental College. Two examiners were included in the study. Study population consisted of patients belonging to the 30-70 years age group. Smokers were grouped into three groups based on the usage of cigarette sticks per day as 1-5 sticks, 6-10 sticks and greater than 10 sticks per day. Based on the years of smoking, they were grouped into three groups1-5 years, 6-10 years and greater than 10 years.

Inclusion and Exclusion Criteria: Patients who smoke 1 and more cigarettes per day for 1 year and more than that were included in the study. Patients with systemic diseases were excluded.

Collection of samples: Total of 20 samples among which case group 10 samples were collected from smokers and control group 10 samples were collected from nonsmokers. Unstimulated saliva samples were collected from the patients using sterile uricol containers. The collected saliva samples were measured for levels of superoxide dismutase enzymes and nitric oxide using spectrophotometric analysis as per standard method. 


\section{Assay of Superoxide dismutase (SOD)}

Procedure: To $0.5 \mathrm{ml} \mathrm{ml}$ of saliva $0.25 \mathrm{ml}$ of ethanol and $1.25 \mathrm{ml}$ of chloroform was added, kept in a mechanical shaker for $15 \mathrm{~min}$ and centrifuged at $20000 \mathrm{xg}$ for $15 \mathrm{~min}$. To $0.5 \mathrm{ml}$ of the supernatant, $2.0 \mathrm{ml}$ of $0.1 \mathrm{M}$ Tris- $\mathrm{HCl}$ buffer $\mathrm{pH} 8.2 ; 1.5 \mathrm{ml}$ of distilled water and $0.5 \mathrm{ml}$ of pyrogallol were added. Change in optical density at 0,1 and $3 \mathrm{~min}$ was read at $420 \mathrm{~nm}$ in a spectrophotometer. Control tubes containing $0.5 \mathrm{ml}$ of distilled water were also treated in a similar manner against a buffer blank. The enzyme activity is expressed as Units/mg protein. One enzyme unit corresponds to the amount of enzyme required to bring about 50\% inhibition of pyrogallol auto-oxidation.

\section{Assay of Nitric oxide (NO)}

Procedure: Briefly, $500 \mu \mathrm{l}$ of salivary was added to $100 \mu \mathrm{l}$ of Gries's reagent, the reaction mixture was incubated for about 5-10 min at room temperature and protected from light. Then colour was developed and measured at 540 $\mathrm{nm}$ in the microplate reader according to the protocol. The results were calculated according to standard curves obtained for standard sodium nitrite $(5-25 \mu \mathrm{M})$, in the same buffer as used for preparation of homogenate using the absorbance measured. The concentration of nitrites as a measure of NO in the examined sample was calculated and expressed in nmoles/mg protein.

Table 2. Shows mean value of nitric oxide levels in smokers and non-smokers. Nitric oxide level is increased in smokers when compared to non smokers (Paired t test, $\mathrm{p}=\mathbf{0 . 0 3 2}$ )

\begin{tabular}{|l|c|c|c|}
\hline $\begin{array}{l}\text { Nitric Oxide } \\
\text { (nmol/mg protein) }\end{array}$ & Mean & $\begin{array}{c}\text { Standard } \\
\text { error of } \\
\text { mean }\end{array}$ & $\begin{array}{c}\text { Paired } \\
\text { t-test }\end{array}$ \\
\hline Smokers & 3.24 & 0.672 & $\begin{array}{c}p \text { value } \\
=0.032\end{array}$ \\
\hline Non Smokers & 1.97 & 0.404 & \\
\hline
\end{tabular}

Figure 2: Bar graph depicts the mean Nitric oxide levels in smokers and non smokers. $\mathrm{X}$ axis denotes smokers and non smokers and $\mathrm{Y}$ axis denotes the mean NO levels (nmol/ $\mathrm{mg}$ protein).It is seen that Nitric oxide level is increased in smokers when compared to non smokers (Paired t test, $\mathrm{p}=0.032$ )

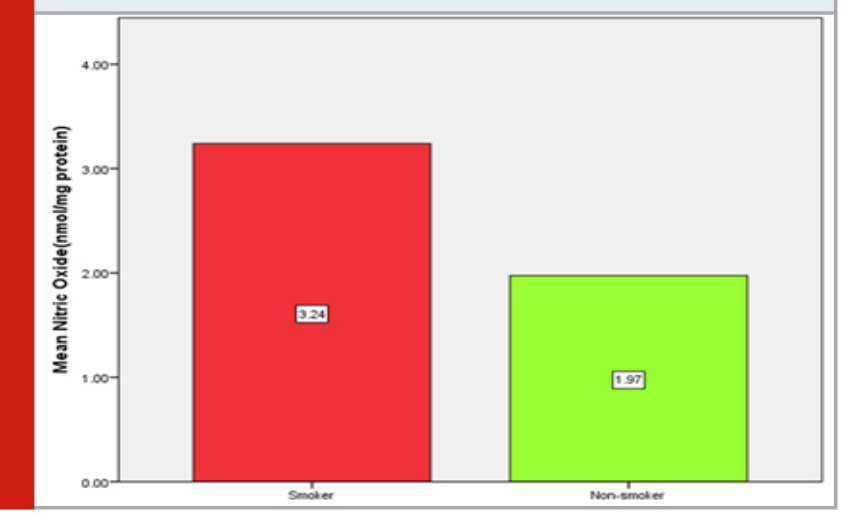

Statistical Analysis: The statistical analysis was performed using the Statistical package for Social Sciences version (SPSS) 20. Differences in mean values between groups were analysed using students' t-test, while association studies were performed using the Pearson's Chi square Test. Values were deemed significant if $\mathrm{p}<0.05$.

\section{RESULTS AND DISCUSSION}

Total of 20 patients, out of which 10 smokers and 10 non-smokers were included in the study.In relation to mean salivary superoxide dismutase levels in smokers and non smokers it was seen that SOD level is increased in non smokers when compared to smokers ,Paired $t$ test, $p=0.018(p<0.05)$, hence statistically significant [Figure 1 and Table 1]. In relation to mean Nitric oxide levels in smokers and non smokers it was seen that Nitric oxide level is increased in smokers when compared to non smokers, Paired t test, $p=0.032(p<0.05)$, hence statistically significant [Figure 2 and Table 2].

Table 3. Shows association between number of cigarette sticks used per day and mean value of Superoxide Dismutase and Nitric Oxide levels. It is seen that as the usage of cigarette sticks increases salivary SOD level decreases which is statistically significant. (Pearson chi square $=8.838$, $p$ value $=0.042$ ) and NO level increases which is statistically significant. (Pearson chi square $=4.330$, $\mathrm{p}$ value $=0.001$ )

\begin{tabular}{|l|c|c|}
\hline $\begin{array}{l}\text { Number of } \\
\text { cigarette sticks } \\
\text { per day }\end{array}$ & $\begin{array}{c}\text { Mean Superoxide } \\
\text { Dismutase } \\
\text { (nmol/mg } \\
\text { protein) }\end{array}$ & $\begin{array}{c}\text { Mean Nitric Oxide } \\
\text { (nmol p value }= \\
0.001 / \mathrm{mg} \\
\text { protein) }\end{array}$ \\
\hline 1-5 sticks & 5.36 & 2.71 \\
\hline 6-10 sticks & 4.72 & 3.13 \\
\hline$>10$ sticks & 4.37 & 3.52 \\
\hline Statistical Test & $\begin{array}{c}\text { Chi square }= \\
8.838\end{array}$ & $\begin{array}{c}\text { Chi square }= \\
4.330 \\
\text { p value }=0.042\end{array}$ \\
\hline
\end{tabular}

In relation to association between number of cigarette sticks used per day and mean value of superoxide dismutase levels it was seen that as the usage of cigarette sticks increases salivary SOD level decreases which is statistically significant. Pearson chi square $=8.838, \mathrm{p}$ value $=0.042(p<0.05)$ and NO level increases which is statistically significant. Pearson chi square $=4.330, \mathrm{p}$ value $=0.001(p<0.05)$ [Figure 3 and Table 3].

In relation to association between number of years of smoking and mean value of superoxide dismutase levels it was seen that as the years of smoking increases salivary SOD level decreases which is statistically significant. Pearson chi square $=7.453$, $p$ value $=0.035(p<0.05)$ and NO level increases which is statistically significant. Pearson chi square $=5.845, p$ value $=0.001(p<0.05)$ [Figure 4 and Table 4]. 
Figure 3: Bar graph shows association between number of cigarettes used per day and mean value of SOD and NO . $\mathrm{X}$ axis denotes number of cigarettes used/day and $\mathrm{Y}$ axis denotes mean SOD and NO (nmol/mg protein). As usage of cigarettes increases salivary SOD level decreases which is statistically significant. (Pearson chi square=8.838, $\mathrm{p}=0.042$ ) and NO level increases which is statistically significant. (Pearson chi square $=4.330, \mathrm{p}=0.001$ )

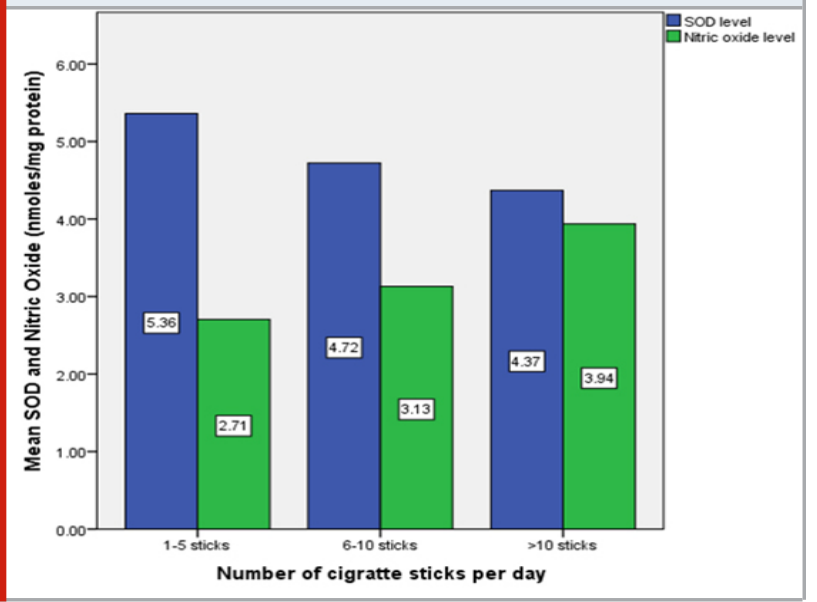

Cigarette smoking has been implicated as a significant risk factor for the establishment and progression of several diseases. Cigarette smoke is a complex mixture of chemical compounds, containing many free radicals and oxidants and may be associated with lower antioxidant concentrations, increased oxidative stress and damage as well as an increased risk of several chronic diseases.

In relation to our study, the mean level of salivary superoxide dismutase level in smokers and non smokers, it was found that level of SOD was significantly increased in smokers which was in line with the study by Mahapatra et al (Mahapatra et al., 2008) and Tavilani et al (Tavilani et al., 2012). The reason behind this is in case of smoking, oxidative stress is created within the cells which leads to production of numerous reactive oxygen species. The reactive oxygen species are dangerous to cells, as they may cause DNA damage. So this is prevented by the action of salivary superoxide dismutase which is an antioxidant that converts reactive oxygen species to hydrogen peroxide which is further degraded to harmless products like water and oxygen. So this defence potential of superoxide dismutase is very important in preventing DNA damage which might lead to tumour progression.

So usually SOD levels are normal in people without smoking habit. In case of smoking this defence potential of SOD is decreased and hence might lead to premalignant conditions and further to tumour progression. However contradictory studies by Zahraei et al (Zahraei et al., 2005), where he observed that no significant difference were observed in SOD levels between smokers and non smokers. The probable reason could be differing sample size, geographic location and differing antioxidant potential of the subjects involved in the study. Also in relation to our study, the number of cigarette sticks used per day and years of smoking it was seen that as these factors increased the level of SOD was decreased significantly, stating that the defence potential of SOD was decreased in case of chronic smokers. This was in line with the study by Kocyigit et al(Kocyigit, Erel and Gur, 2001). Therefore, The decreased level of SOD in smokers indicates the protective role of this antioxidant is decreased and hence the determination of this biomarker would contribute to early diagnosis and prevention of premalignant condition.

Table 4. Shows association between number of years of smoking and mean value of Superoxide Dismutase and Nitric Oxide levels . It is seen that as the years of smoking increases salivary SOD level decreases which is statistically significant. (Pearson chi square $=7.453$, p value $=0.035$ ) and NO level increases which is statistically significant. (Pearson chi square $=5.845, p$ value $=0.001$ ).

\begin{tabular}{|l|c|c|}
\hline $\begin{array}{l}\text { Number of years } \\
\text { of smoking }\end{array}$ & $\begin{array}{c}\text { Mean Superoxide } \\
\text { dismutase } \\
\text { (nmol/mg } \\
\text { protein) }\end{array}$ & $\begin{array}{c}\text { Mean Nitric } \\
\text { Oxide } \\
\text { (nmol/mg } \\
\text { protein) }\end{array}$ \\
\hline 1-5 years & 5.36 & 2.71 \\
\hline 6-10 years & 4.72 & 3.13 \\
\hline >10 years & 4.37 & 3.94 \\
\hline Statistical Test & $\begin{array}{c}\text { Chi square } \\
=7.453 \\
\text { p value }=0.035\end{array}$ & $\begin{array}{c}\text { Chi square } \\
=5.845 \\
\text { p value }=0.001\end{array}$ \\
\hline
\end{tabular}

Figure 4: Bar graph shows association between number of years of smoking and mean value of SOD and NO. X axis denotes number of years of smoking and $\mathrm{Y}$ axis denotes mean SOD and NO (nmol/mg protein). As years of smoking increases SOD level decreases which is statistically significant. (Pearson chi square $=7.453, \mathrm{p}=0.035$ ) and NO level increases which is statistically significant. (Pearson chi square $=5.845, \mathrm{p}=0.001$ ).

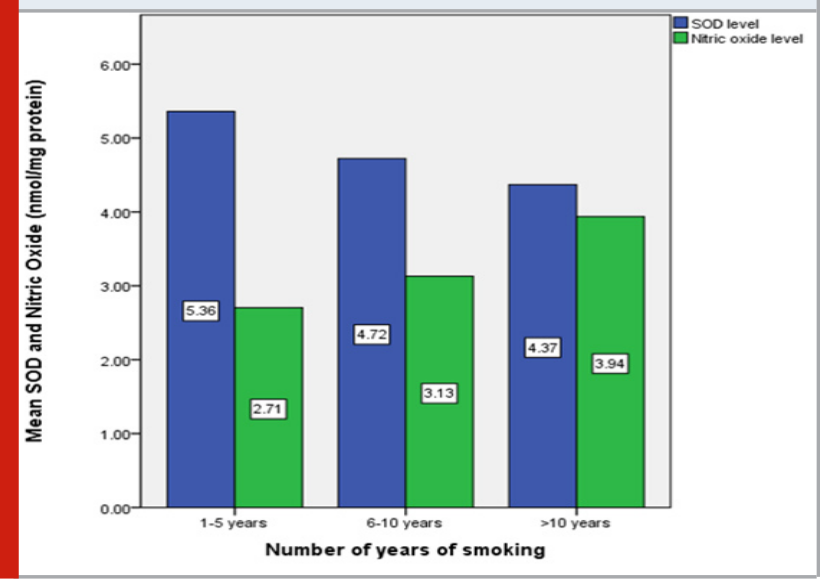

In relation to our study, the mean level of nitric oxide in smokers and non-smokers it was seen that the level of nitric oxide was increased in case of smokers. This 
was in line with the study by Sunitha et al (Sunitha and Shanmugam, 2006) and. The reason being in case of smoking, there is an inflammatory reaction which occurs in the cells of oral mucosa which stimulates the $\mathrm{T}$ lymphocytes and macrophages to induce enzyme nitric oxide synthase which produces nitric oxide. This nitric oxide reacts with other free radicals to form a carcinogenic component peroxynitrite which induces DNA damage which further leads to tumour progression. So in case of non-smokers there is no inflammatory reaction occuring, and hence there is no much release of nitric oxide. However contradictory findings were seen in a study by Patel(Patel et al., 2009), where the level of NO was increased in case of smokers when compared to non smokers but was not statistically significant.

The reason could be differing sample size, geographic location and immune potential of the subjects involved in the study. Also in relation to our study, the number of cigarette sticks used per day and number of years of smoking it was seen that as these factors increased the level of NO increased significantly. The reason for this could be as the frequency of smoking increases, there would be increased inflammatory reaction occuring resulting in the increased release of NO causing DNA damage. In healthy people the release of $\mathrm{NO}$ in response to inflammatory reaction is combated by the release of antioxidants like SOD which decreases the NO level, thus preventing DNA damage. This was in line with the study by Ohashi et al(Ohashi, Iwase and Nagumo, 1999). Therefore, increased levels of Nitric oxide in smokers indicate that NO have a pathophysiological role in occurrence of oral lesion caused due to smoking. So the determination of this biomarker would contribute to early diagnosis and prevention of premalignant conditions.

The limitations of the study are small sample size, examiner's subjectivity. The future scope of this study is to do intensive research with large sample size and also saliva is the first fluid that is exposed during smoking and its antioxidant system plays an important role in anti-cancer potential. So saliva is one which is easily accessible for research purposes and determination of these biomarkers in saliva would contribute to early diagnosis and prevention of premalignant conditions.

\section{CONCLUSION}

Within the limits of the study, it is seen that there is a highly significant increase in the nitric oxide levels and decrease in the superoxide dismutase enzyme level in smokers when compared to that of non smokers. Also there is a significant increase in the level of NO and decrease in the level of SOD as the number of cigarette sticks and years of smoking increased. Estimation of salivary nitric oxide levels and superoxide dismutase levels is a simple, non invasive procedure and could be analysed to suggest the role of these biomarkers in the pathogenesis of oral lesions.

\section{ACKNOWLEDGEMENTS}

I wish to express my deep sense of gratitude and professional thanks to my research guide Dr. Sreedevi, Senior Lecturer, Department of Oral Medicine and Radiology, Saveetha Dental College and my college management for their keen interest, inspiring guidance , constant encouragement with my work during all stages to complete this study.

Author's Contribution: First author Vaishali.S performed data collection, analysis and interpretation and wrote the manuscript. Second author Sreedevi Dharman contributed to conception, study design, analysis, interpretation and critically revised the manuscript. All the authors have discussed the results and contributed to the final manuscript.

\section{Conflict of Interest: None}

\section{REFERENCES}

Alcaraz, M. J. and Guilln, M. I. (2002) 'The nitric oxide related therapeutic phenomenon: a challenging task', Current pharmaceutical design, 8(3), pp. 215-231.

Bolzán, A. D., Bianchi, M. S. and Bianchi, N. O. (1997) 'Superoxide dismutase, catalase and glutathione peroxidase activities in human blood: influence of sex, age and cigarette smoking', Clinical biochemistry, 30(6), pp. 449-454.

Crowell, J. A. et al. (2003) 'Is inducible nitric oxide synthase a target for chemoprevention?', Molecular cancer therapeutics, 2(8), pp. 815-823.

Golusinska-Kardach, E. et al. (2015) '[Periodonta disease in smokers, and the parameters of oxidative stress]', Przeglad lekarski, 72(10), pp. 584-587.

Kocyigit, A., Erel, 0. and Gur, S. (2001) 'Effects of tobacco smoking on plasma selenium, zinc, copper and iron concentrations and related antioxidative enzyme activities', Clinical biochemistry, 34(8), pp. 629-633.

Mahapatra, S. K. et al. (2008) 'Smoking induced oxidative stress in serum and neutrophil of the university students', Al Ameen J Med Sci, 1(1), pp. 20-31.

Mayne, S. T. (2003) 'Antioxidant nutrients and chronic disease: use of biomarkers of exposure and oxidative stress status in epidemiologic research', The Journal of nutrition, 133 Suppl 3, p. 933S-940S.

Ohashi, M., Iwase, M. and Nagumo, M. (1999) 'Elevated production of salivary nitric oxide in oral mucosal diseases', Journal of oral pathology \& medicine: official publication of the International Association of Oral Pathologists and the American Academy of Oral Pathology, 28(8), pp. 355-359.

Patel, J. B. et al. (2009) 'Role of nitric oxide and antioxidant enzymes in the pathogenesis of oral cancer', Journal of cancer research and therapeutics, 5(4), pp. 247-253.

Patil, S. R. et al. (2018) 'Comparative Study of the 
Efficacy of Newer Antioxitands Lycopene and Oxitard in the Treatment of Oral Submucous Fibrosis', Pesquisa brasileira em odontopediatria e clinica integrada, 18(1), pp. 1-7.

Patil, S. R. et al. (2018) 'Three-Rooted Mandibular First Molars in a Saudi Arabian Population: A CBCT Study', Pesquisa brasileira em odontopediatria e clinica integrada, 18(1), p. e4133.

Patil, S. R. et al. (2020) 'Assessment of Maximum Bite Force in Oral Submucous Fibrosis Patients: A Preliminary Study', Pesquisa brasileira em odontopediatria e clinica integrada. (Histopathological studies before and after kepacort in oral submucous fibrosis), 20, p. 482.

Rodgman, A. and Perfetti, T. A. (2013) The Chemical Components of Tobacco and Tobacco Smoke, Second Edition. CRC Press.

Simic, M. G. and Karel, M. (2013) Autoxidation in Food and Biological Systems. Springer Science \& Business Media.

Subramaniam, N. and Muthukrishnan, A. (2019) 'Oral mucositis and microbial colonization in oral cancer patients undergoing radiotherapy and chemotherapy: A prospective analysis in a tertiary care dental hospital', Journal of investigative and clinical dentistry, 10(4), p. e12454.

Sunitha, M. and Shanmugam, S. (2006) 'Evaluation of salivary nitric oxide levels in oral mucosal diseases: A controlled clinical trial', Indian journal of dental research: official publication of Indian Society for Dental Research, 17(3), pp. 117-120.

Tavilani, H. et al. (2012) 'Oxidative stress in COPD patients, smokers, and non-smokers', Respiratory care, 57(12), pp. 2090-2094.

Toker, H. et al. (2012) 'Influence of smoking on interleukin-1beta level, oxidant status and antioxidant status in gingival crevicular fluid from chronic periodontitis patients before and after periodontal treatment', Journal of periodontal research, 47(5), pp. 572-577.

U. s. Department of Health and Human Services Staff (2010) How Tobacco Smoke Causes Disease: The Biology and Behavioral Basis for Smoking-attributable Disease : a Report of the Surgeon General. U.S. Department of Health and Human Services, Public Health Service, Office of the Surgeon General.

Vadivel, J. K. et al. (2019) 'Mast cell expression in oral lichen planus: A systematic review', Journal of investigative and clinical dentistry, 10(4), p. e12457.

Zahraei, M. et al. (2005) 'Effects of cigarette smoking on erythrocyte antioxidative enzyme activities and plasma concentrations of their cofactors'. sid.ir. Available at: https://www.sid.ir/en/journal/ViewPaper. aspx?ID=38037.

Zenzes, M. T. (2000) 'Smoking and reproduction: gene damage to human gametes and embryos', Human reproduction update, 6(2), pp. 122-131. 